\title{
The simulation model of the exhaust flue gas cooler in 300MW oxy-coal fired boiler
}

\author{
Jianqiang Gao ${ }^{1, a}$, Shaodong Sun ${ }^{2, b}$ \\ ${ }^{1}$ School of Energy Power and Mechanical Engineering, North China Electric Power University, \\ Baoding 071003, China. \\ ${ }^{2}$ School of Energy Power and Mechanical Engineering, North China Electric Power University \\ Baoding 071003, China. \\ a,bsun1163398838@126.com
}

Keywords: 300MW oxy-coal fired boiler; exhaust flue gas cooler; simulation model

\begin{abstract}
The exhaust flue gas cooler in a 300MW oxy-coal fired boiler is taken as an object of study. The simulation model of the cooler was established by the method of lumped parameter. The change rule of the exhaust flue gas cooler parameters and the flue gas thermal physical property parameters were analyzed by the disturbance of the coal feeder speed. It is found that, the simulation model of exhaust flue gas cooler was established basing on the conservation laws of mass and energy. The simulation experiment results show that the change rules of main operational parameters and the flue gas thermal physical property parameters in the exhaust flue gas cooler can be reasonably presented by the model with the speed disturbance of coal feeder, which can be the reference for the design and the operation control of the flue gas coolers.
\end{abstract}

\section{Introduction}

The oxy-coal fired mode is one of the most promising and research valuable technologies of $\mathrm{CO}_{2}$ emission reduction. In this way it can be used to eliminate $\mathrm{CO}_{2}$ emissions in pulverized coal fired boiler unit ${ }^{[1]}$. Shown as Fig.1, after cooled and dehydrated, a part of exhaust flue gas is used as primary recycle gas, which is essential for the needs of the pulverized coal drying and conveying; On the other hand, the rest of the flue gas is sent to flue gas compression system. In the flue gas compression system, pressure of the flue gas is increased and most moisture of the flue gas is dehydrated by multistage compression and cooling, which are beneficial for further purification and recovery of flue gas ${ }^{[2]}$.

The gas cooler has been widely used in the oxy-coal fired boiler unit and its performance has influence on the dryness of pulverized coal and the safe and economy operation of the flue gas compressor. When the exhaust flue gas cooler has the working performance degradation, the moisture of the recycle flue gas increases following with the drop of its drying ability of pulverized coal, which is harmful to the furnace combustion. What is more, when the flue gas cooler in the compression system has the working performance degradation, the increase of its outlet temperature or water vapor fraction is not conducive to the economic and security operation of flue gas compressor. It is better to obtain the change rules of main parameters of gas cooler with external disturbance, which has principle significance to ensure the economic and safe operation of the unit. With the establishment of simulation model of the flue gas compression system in a 300MW oxy-coal fired boiler unit with the method of lumped parameter, the change rules of the gas cooler parameters is studied with the coal feeder speed disturbance, which provides the reference for the improvement of the design and the control of these flue gas coolers. 
The exhaust flue gas The primary recycle gas

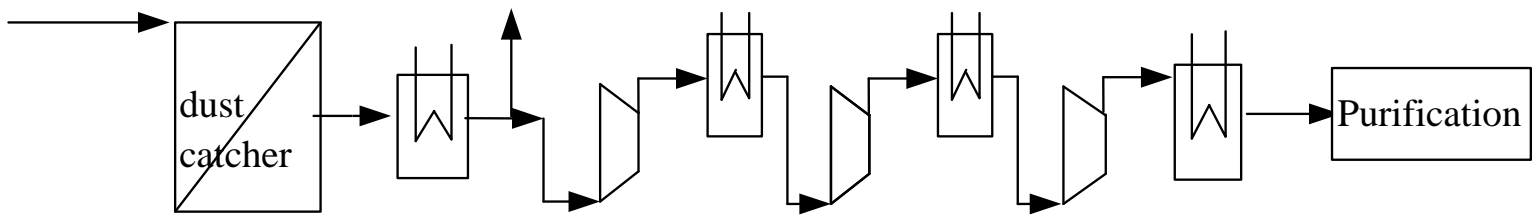

The exhaust flue gas cooler Multistage compression and cooling

Fig.1 The exhaust flue gas process of a $300 \mathrm{MW}$ oxy-coal fired boiler

\section{Mathematical model ${ }^{[3]}$}

The exhaust flue gas cooler is recupe rator, in which flue gas heat transfer is presented by scouring horizontally staggered tube bundles. The simulation model of the cooler was established by the method of lumped parameter.

The energy equation of the flue gas side:

$$
\rho_{\mathrm{fg}} V_{\mathrm{fg}} C_{\mathrm{pfg}} \frac{\mathrm{d} T_{\mathrm{fg}}^{\prime \prime}}{\mathrm{d} \tau}=G_{\mathrm{fg}}^{\prime} C_{\mathrm{pfg}} T_{\mathrm{fg}}^{\prime}-G_{\mathrm{fg}}^{\prime \prime} C_{\mathrm{pfg}} T_{\mathrm{fg}}^{\prime \prime}-Q_{\mathrm{fg}-\mathrm{m}}+r M_{\text {water }}
$$

Where $T_{\text {fg }}^{\prime}, T_{\text {fg }}^{\prime \prime}$ are respectively the inlet temperature and the outlet temperature of the flue gas, ${ }^{\circ} \mathrm{C} ; G_{\mathrm{fg}}^{\prime}, G^{\prime \prime}{ }_{\mathrm{fg}}$ are respectively the inlet flow and the outlet flow of the flue gas, $\mathrm{kg} / \mathrm{s} ; \rho_{\mathrm{fg}}$ is the density of the flue gas, $\mathrm{kg} / \mathrm{m}^{3} ; V_{\mathrm{fg}}$ is the volume of the flue gas, $\mathrm{m}^{3} ; C_{\mathrm{pfg}}$ is the specific heat of the flue gas, $\mathrm{J} /(\mathrm{kg} \cdot \mathrm{k}) ; Q_{\mathrm{fg}}-\mathrm{m}$ is the heat release from the flue gas to the metal pipe wall, $\mathrm{kJ} / \mathrm{s} ; r$ is the average latent heat of per unit steam, which have corresponding partial pressure of the inlet and the outlet flue gas, $\mathrm{kg} / \mathrm{s} ; M_{\text {water }}$ is the flue gas breeding ${ }^{[4]}, \mathrm{kg} / \mathrm{s}$.

According to the law of conservation of mass, the mass of the inlet and the outlet flue gas flow remains constant in the heat transfer process:

$$
G_{\mathrm{fg}}^{\prime}=G_{\mathrm{fg}}^{\prime \prime}+M_{\text {water }}
$$

Where $G_{\mathrm{fg},}^{\prime} G_{\mathrm{fg}}^{\prime \prime}$ are respectively the inlet and the outlet mass flow of the flue gas, $\mathrm{kg} / \mathrm{s}$;

According to the heat transfer equation, the heat transfer rate from the flue gas to the metal pipe wall is obtained:

$$
\begin{gathered}
Q_{\mathrm{fg}-\mathrm{m}}=\theta H \alpha_{\mathrm{fg}}\left(\frac{\left(T_{\mathrm{fg}}{ }^{\prime}+T_{\mathrm{fg}}{ }^{\prime \prime}\right)}{2}-T_{\mathrm{m}}\right) \\
\alpha_{\mathrm{fg}}=0.358 \mathrm{C}_{\mathrm{s}} C_{\mathrm{z}} C_{\mathrm{w}}\left(\frac{\lambda}{d}\right)\left(\frac{w d}{v}\right)^{0.6} \operatorname{Pr}^{0.33}
\end{gathered}
$$

Where $\theta$ is the correction coefficient of logarithmic temperature ${ }^{[5]} ; H$ is the heat exchange area, $\mathrm{m}^{2} ; a_{\mathrm{fg}}$ is the convective heat transfer coefficient of the flue gas and the metal pipe wall, $\mathrm{W} /\left(\mathrm{m}^{2} \cdot \mathrm{K}\right)$; $T_{\mathrm{m}}$ is the average temperature of the metal pipe wall, ${ }^{\circ} \mathrm{C} ; \lambda$ is thermal conductivity of the flue gas in average temperatures, $\mathrm{W} /(\mathrm{m} \cdot \mathrm{K}) ; d$ is the metal pipe diameter, $\mathrm{m} ; \omega$ is the flow velocity of the flue gas, $\mathrm{m} / \mathrm{s} ; v$ is the kinematic viscosity of flue gas in average temperatures, $\mathrm{m}^{2} / \mathrm{s}$; $P r$ is the Prandtl number of flue gas in average temperatures; $\mathrm{C}_{\mathrm{S}}, \mathrm{C}_{\mathrm{Z}}, \mathrm{C}_{\mathrm{W}}$ are respectively the correction coefficient of horizontal intercept and vertical intercept, the correction coefficient of tube row number and the correction coefficient of flue gas temperature and component.

\section{Simulation test and analysis}

On the condition of BMCR, the experiment of coal feeder speed disturbance focuses on the change rules of main operational parameters and the flue gas thermal physical property parameters in the exhaust flue gas cooler with the change of furnace coal. The main structure parameters of the exhaust flue gas cooler are shown in Tab.1. 
Tab.1. Exhaust flue gas structured data

\begin{tabular}{cccc}
\hline Items & \multicolumn{4}{c}{ Items } \\
\hline Pipe external diameter Dout/m & 0.064 & Tube row number Z2 & 21 \\
Pipe inner diameter $D$ in $/ \mathrm{m}$ & 0.050 & Flue gas flow area $H_{\mathrm{g}} / \mathrm{m}^{2}$ & 1.0 \\
Horizontal intercept $s_{1} / \mathrm{m}$ & 0.234 & Cooling water flow area $H_{\mathrm{w}} / \mathrm{m}^{2}$ & 0.1 \\
Vertical intercept $s_{2} / \mathrm{m}$ & 0.116 & Heat exchange area $H / \mathrm{m}^{2}$ & 6500 \\
\hline
\end{tabular}

Shown as Fig.2-3 and Tab.2, as the speed of coal feeder decreases by $5 \%$, it is found that the inlet gas flow $G_{\mathrm{fg}}$ of the exhaust flue gas cooler decreases, which leads to the decrease of flue gas heat release $Q_{\mathrm{fg}-\mathrm{m}}$. However, the main cause of the decrease outlet gas temperature $T_{\mathrm{fg}}$ is considered to be the decrease of heat release $Q_{\mathrm{fg}-\mathrm{m}}$, which leads to the lower temperature of metal pipe wall and the outlet flue gas. Owing to the great thermal inertia of cooling water and metal pipe wall in exhaust flue gas cooler, the gas temperature changes more slowly and its transition time is much longer than that of the flue gas flow $G_{\mathrm{fg}}^{\prime}$. Furthermore, the decrease of the flue gas breeding $M_{\text {water }}$ up to $0.65 \mathrm{~kg} / \mathrm{s}$ results from the decrease of inlet gas flow $G_{\mathrm{fg}}^{\prime}$ and drop of water vapor fraction in the inlet flue gas.

On the other hand, it is found that the drop of flue gas convective heat transfer coefficient $\alpha_{\mathrm{fg}}$ is another factor of the decrease of flue gas heat release $Q_{\mathrm{fg}-\mathrm{m}}$. At the same time, the decrease of $\mathrm{CO}_{2}$ fraction and $\mathrm{H}_{2} \mathrm{O}$ fraction, the increase of $\mathrm{O}_{2}$ fraction in inlet flue gas are considered to lead to the increase of kinematic viscosity $v$; The drop of gas flow velocity $\omega$ is following with the decrease of inlet gas flow $G_{\mathrm{fg}}^{\prime}$; Likewise, the decrease of flue gas thermal conductivity $\lambda$ is also following with the drop of flue gas temperature; The increase of the Prandtl number $P_{r}$ is mainly due to the decrease of the flue gas thermal conductivity coefficient $\lambda$, as well as the increase of density and kinematic viscosity. Thus, it can draw a conclusion that the principal factors for the drop of flue gas convective heat transfer coefficient $\alpha_{\mathrm{fg}}$ are the thermal conductivity $\lambda$, the flow velocity $\omega$ and the kinematic viscosity $v$ of the flue gas, but not the Prandtl number $P_{r}$.

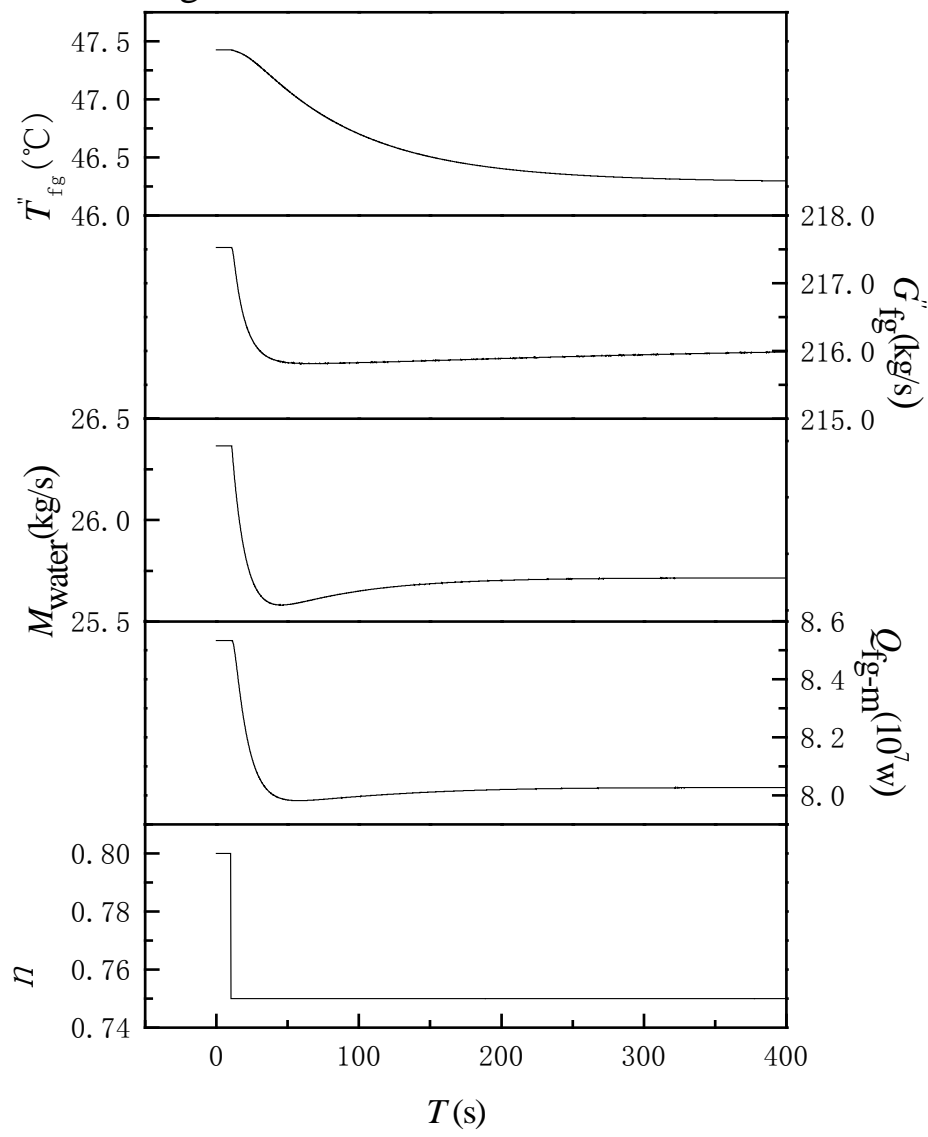

Fig.2 the operational parameters change curves of the exhaust flue gas cooler 


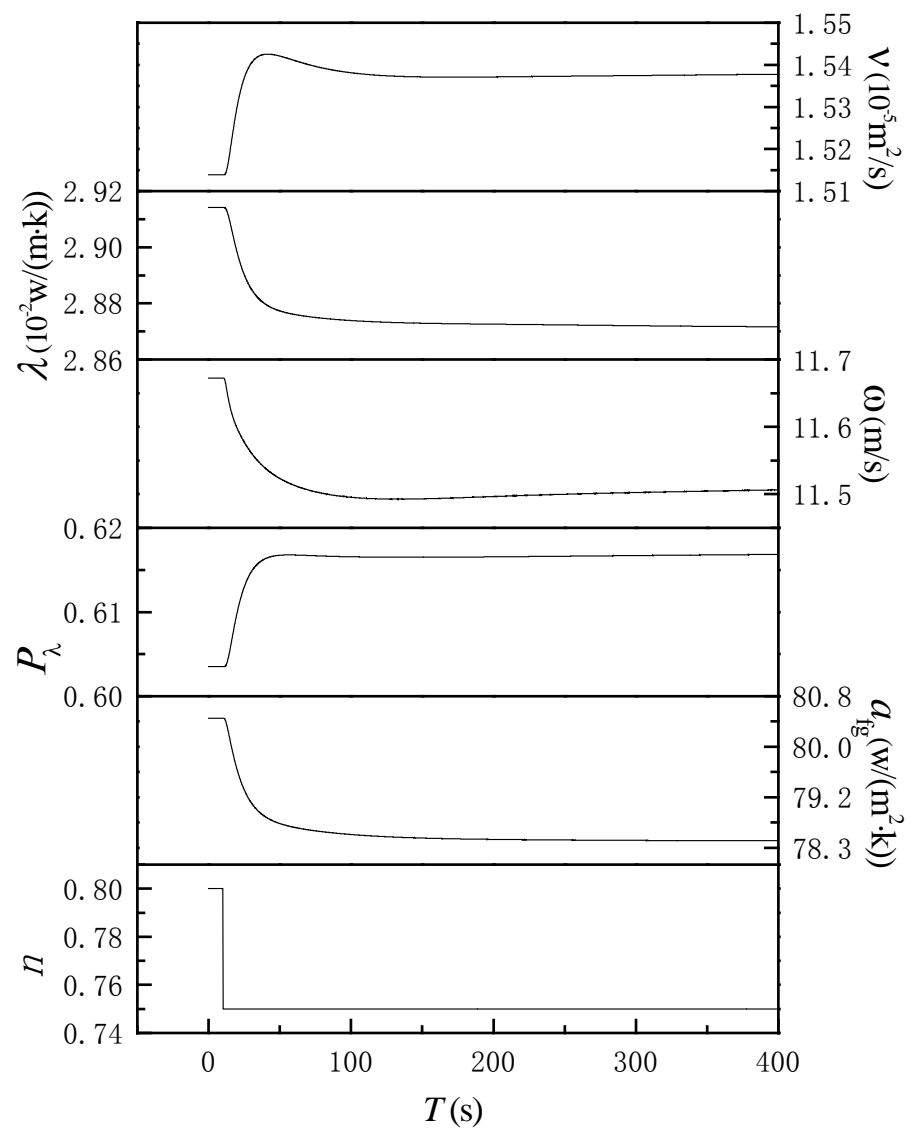

Fig.3 the parameters change curves of the exhaust flue gas cooler

Tab.2 Exhaust flue gas cooler parameters table

\begin{tabular}{ccccc}
\hline Items & $\begin{array}{c}\text { Before the } \\
\text { disturbance }\end{array}$ & $\begin{array}{c}\text { After the } \\
\text { disturbance }\end{array}$ & $\begin{array}{c}\text { Amplitude of } \\
\text { variation } / \%\end{array}$ & $\begin{array}{c}\text { Transition } \\
\text { time } / \mathrm{s}\end{array}$ \\
\hline Outlet temperature of flue gas $T_{\mathrm{fg}}^{\prime \prime} /{ }^{\circ} \mathrm{C}$ & 47.42 & 46.29 & -0.02 & 250 \\
Inlet flue gas flow $G_{\mathrm{fg}}^{\prime} /\left(\mathrm{kg}^{-1} \mathrm{~s}^{-1}\right)$ & 217.53 & 216.03 & -0.69 & 30 \\
Flue gas breeding $M_{\mathrm{waterch}} /\left(\mathrm{kg}^{-1} \mathrm{~s}^{-1}\right)$ & 26.36 & 25.71 & -2.47 & 30 \\
$\begin{array}{c}\text { Flue gas heat release } Q_{\mathrm{fg}-\mathrm{m}} / 10^{7} \mathrm{w} \\
\text { Flue gas kinematic viscosity } \mathrm{v} /\end{array}$ & 8.53 & 8.03 & -5.94 & 35 \\
$\left(10^{-5} \mathrm{~m}^{2} / \mathrm{s}\right)$ & 1.51 & 1.54 & 1.61 & 60 \\
$\begin{array}{c}\text { Flue gas thermal conductivity } \\
\lambda /\left(10^{-2} \mathrm{w} /(\mathrm{m} \cdot \mathrm{K})\right)\end{array}$ & 2.91 & 2.87 & -1.47 & 55 \\
$\begin{array}{c}\text { Flue gas Prandtl number } P_{r} \\
\text { Flue gas flow velocity } \omega /\left(\mathrm{m}^{-1} \mathrm{~s}^{-1}\right)\end{array}$ & 0.60 & 0.62 & 2.24 & 40 \\
Flue gas convective heat transfer & 11.67 & 11.51 & -1.38 & 50 \\
coefficient $\alpha_{\mathrm{fg}}\left(\mathrm{W} /\left(\mathrm{m}^{2} \cdot \mathrm{K}\right)\right.$ & 80.47 & 78.45 & -2.51 & 50 \\
\hline
\end{tabular}

\section{Summary}

The simulation model of exhaust flue gas cooler was established basing on the conservation laws of mass and energy. The simulation experiment results show that the change rules of main operational parameters and the flue gas thermal physical property parameters in the exhaust flue gas cooler can be reasonably presented by the model with the speed disturbance of coal feeder, which can be the reference for the design and the operation control of the flue gas coolers. 


\section{References}

[1]Weiping Yan, Cuili Mi. Study on conceptual design of utility boiler burning oxygen-enriched pulverized coal[J]. Thermal Power Generation, 2011,40(02):1-7.

[2] Hongbin Kong, Chaohui Liu, Sheng Chen, et al.Process Simulation and Optimization of a 600 MW O2/CO2 Power Plant[J].Proceedings of the CSEE,2012,32(2):53-60.

[3]Chunkai Feng, Junting Shen. Boiler principle and calculation [M] Beijing: Science Press, 2003

[4]Zhong Xu. Centrifugal compressor principle [M]. Beijing: China Machine Press, 1990.

[5]Zhifu Hou. Study of Real-time Simulation Model for Oxy-coal Fired Boiler Unit[D]. North China Electric Power University, 2012. 